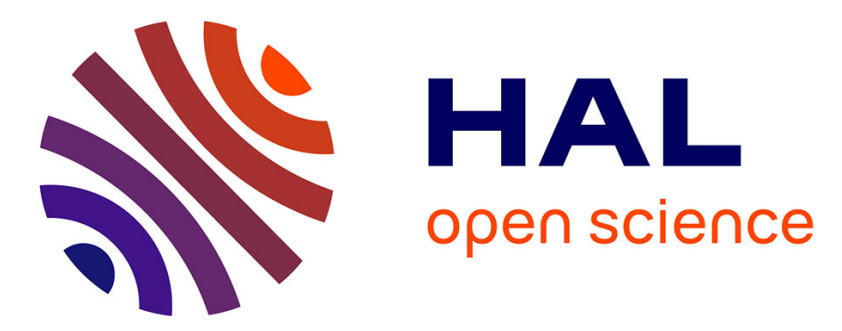

\title{
An ecological multi-Level theory of competition for resources used to analyse density-dependence effects in fruit production
}

Michel M. Génard, Francoise F. Lescourret, Zhanwu Z. Dai, Marion Prudent

\section{To cite this version:}

Michel M. Génard, Francoise F. Lescourret, Zhanwu Z. Dai, Marion Prudent. An ecological multiLevel theory of competition for resources used to analyse density-dependence effects in fruit production. 29. International Horticultural Congress 2014, International Society for Horticultural Science (ISHS). INT., Aug 2014, Brisbane, Australia. hal-02742816

\section{HAL Id: hal-02742816 https://hal.inrae.fr/hal-02742816}

Submitted on 3 Jun 2020

HAL is a multi-disciplinary open access archive for the deposit and dissemination of scientific research documents, whether they are published or not. The documents may come from teaching and research institutions in France or abroad, or from public or private research centers.
L'archive ouverte pluridisciplinaire HAL, est destinée au dépôt et à la diffusion de documents scientifiques de niveau recherche, publiés ou non, émanant des établissements d'enseignement et de recherche français ou étrangers, des laboratoires publics ou privés. 


\title{
An Ecological Multi-Level Theory of Competition for Resources Used to Analyse Density-Dependence Effects in Fruit Production
}

\author{
M. Génard and F. Lescourret \\ Z. Dai \\ INRA, UR1115 Plantes \\ et Systèmes de culture Horticoles \\ INRA, UMR1287 EGFV , ISVV \\ Bordeaux \\ Avignon \\ France \\ France \\ B. Quilot-Turion \\ INRA, UR1052, Génétique et Amélioration \\ M. Prudent \\ des Fruits et Légumes \\ INRA, UMR1347 Agroécologie \\ Dijon \\ Avignon \\ France \\ France
}

Keywords: Competition, population, multi-level, cell, fruit, mass, modeling

\begin{abstract}
Lescourret and Génard (2003) developed a multi-level theory of competition for resources applied to fruit production, considering that any collection of unit parts (cells or seeds in a fruit, fruits in an infructescence or in a tree,...) can form a population and the population is subject to competition, whatever the level of organization. The principles of the theory are that the mass of each unit decreases when the number of units in the population increases and that the total mass of the population increases as the number of units increases until it reaches a maximum, after which it decreases. A three-parameter model based on that theory was used to analyze the level of density-dependence, i.e. the effect of the population size on its mass. Comparing the number of cells and the mean cell volume in mesocarp of fruits from peach genotypes showed a strong and undercompensating density-dependence that revealed competition between cells. Similarly, when comparing populations for different fruit species, similar results or exact compensation were observed for several levels (fruit, infructescence, tree...). Because undercompensating or exact density-dependence were found in most of the cases, a simpler two parameter model was proposed by Prudent et al. (2013). This two parameter model was used to analyse the genetic control of competition between seeds in multi-seeded fruits.
\end{abstract}

\section{INTRODUCTION}

In cultivated species, fruit mass is an important criterion of attractiveness to consumers and it is one of the main criteria in determining the grower's benefit. In addition, fruit yield is essential for the growers and the requirements of the human population. The processes of plant domestication and breeding have placed emphasis on the selection for big fruits and high yield. Fruit mass and yield are modulated by competition for resources. This competitive process occurs at several levels of organization. Indeed, the yield of an orchard is the result of yield per tree, itself resulting from fruit growth, which is the result of cell growth. A population can be defined at each 
level, for example, a fruit can be viewed as a population of cells or a population of seeds and the associated flesh. Similarly, an infructescence or a plant can be viewed as a population of fruits.

Lescourret and Génard (2003) and then Prudent et al. (2013) have developed a simple theoretical framework dealing with competition for resources, which is valid regardless of the level of organization. According to this theory, the mass of each individual of the population decreases when the number of individuals increases within the population, because of competition for resources. This theory is clearly situated within the framework of density-dependent effects of intraspecific competition, which have been studied for various vegetal and animal organisms (Begon et al., 1996).

The aim of this paper is to give an overview of the research undertaken in this field since 10 years (see Lescourret and Génard, 2003; Quilot and Génard, 2008; Prudent et al. 2013). The usefulness of the theory to describe the competition on various scales and for different species will be first presented. The competition for resources will be then analysed for contrasted carbon supplies and genotypes.

\section{MATERIALS AND METHODS}

The theory developed by Lescourret and Génard (2003) observes two main principles: (i) given a population of $n$ units (cell, seed, fruit,...), the mass of each unit decreases when the number of units in the population increases, because of increasing competition for resources, possibly after a plateau, and (ii) the total mass of the population increases as the number of units increases until it reaches an optimum level, after which it decreases because of excessive competition between units.

These two principles are described through two equations with three parameters:

$$
\begin{aligned}
& \mathrm{M}=M_{\text {max }}\left(1-\left(\frac{\mathrm{n}}{n_{\max }}\right)^{\alpha}\right) \\
& \mathrm{TM}=\mathrm{n} \mathrm{M}
\end{aligned}
$$

where $\mathrm{M}$ is the mean unit mass and TM the population mass. $M_{\max }$ and $n_{\max }$ are the maximal mass per unit and the maximal number of units, respectively. $\alpha$ is positive and gives the shape of the relationship (Fig. 1a). The lower $\alpha$ is, the more competition between units is. When $\mathrm{n}$ increases towards $n_{\max }$, M decreases towards zero. In practice, $\mathrm{n}$ never reaches $n_{\max }$. The maximal population mass TMmax is reached for an optimal number of units,

$$
\mathrm{n}_{\mathrm{opt}}=\frac{n_{\max }}{(\alpha+1)^{\frac{1}{\alpha}}}
$$

When the population is a collection of individual plants, the numbers per unit area are considered, in which case $\mathrm{n}, n_{\max }$ and $\mathrm{n}_{\mathrm{opt}}$ are densities. Accordingly, TM and $\mathrm{TM}_{\max }$ are expressed per unit area.

Because TM does not reach a maximum in most of the cases, the initial threeparameter model was simplified to a model with two parameters (Prudent et al., 2013),

$$
\mathrm{M}=\frac{M_{\max }}{n^{\beta}}
$$

Here too $M_{\max }$ is the maximum weight of an individual and $\beta$ reflect the level of competition (Fig. 1b).

\section{RESULTS AND DISCUSSION}




\section{The multi-level theory applies to a large range of plant and organizational levels}

Figure 2 shows that our multi-level theory of competition could be applied to a large range of plant and organizational levels. An important feature of the theory is that the mass of the units of the population can decrease with the number of units, which is observed most of the time (Fig. 2). This means that there is a strong density-dependence effect and a competition for resources between units.

From a theoretical point of view, when density-dependence occurs, three distinct situations of density-dependent effects appear, according to the number of units (Fig. 1). The first one is undercompensating density-dependence, with increases in the number of units leading to increases in total fruit mass, in spite of competition (Begon et al., 1996). The second one is exactly compensating density-dependence, where the total fruit mass is maintained at a constant level. In Fig. 1, this region, strictly speaking, is restricted to a maximum obtained for a number of units called $\mathrm{n}_{\mathrm{opt}}$. The third situation, which begins when the number of units exceeds $n_{o p t}$, is overcompensating density-dependence, with a greater competition effect, leading to decrease in total fruit mass.

When considering available data, it appears that undercompensation densitydependence was encountered in most cases, a possible interpretation being that "normal" ranges of unit numbers (i.e., those observed in nature or fields) are unable to lead to overcompensation. Undercompensation means either that the resource is always large enough to allow the increase of the population mass or that the population can act on the availability of resources. For example, at the fruit level, the seed number could influence the translocation of assimilates through a hormonal control of the differentiation of vascular tissues (Antognozzi et al., 1991).

However, overcompensation was shown, mainly at the plant collection level. Indeed, plant competition for resources can be stiff at this level. For example, Génard et al. (2000) showed that photosynthetic levels in peach trees, planted at a density of 2,500 trees/ha, was only 50 to $70 \%$ the rate of photosynthesis of an isolated tree, due to the mutual shadow of leaves able to be critical at high plant density. Clearly, some trends toward an optimal number of units appear to exist, as predicted by the theory.

\section{Resource availability and genotypes affect competition}

1. Leaf:fruit ratio affects differently grape and tomato. The leaf:fruit ratio was manipulated in grape and tomato in order to vary the $\mathrm{C}$ availability. Generally, lower leaf:fruit ratio resulted in smaller berries for a given seed number (Fig. 3). Using the two parameter model of Prudent et al. (2013) we have shown that the decreasing grape berry size with increasing fruit load in a particular seed number group was accounted for by decreases in the maximal size of a unit $M_{\max }$, whereas $\beta$ was largely unaffected. On the opposite, $\beta$ which reflects the level of competition is largely affected in tomato fruit. The underlying mechanism responsible for the differences in the response to carbon supply between grape and tomato remains unknown.

2. Genetic control of competition. We studied, using the three parameters model of Lescourret and Génard (2003) four groups of peach genotypes which display large variations in fruit size related to the percentage of wild species genome $(P$. davidiana) in their own genome. According to our results, large difference of fruit size resulted from variations in cell number, whatever the genotype. Moreover, the mean cell volume was decreasing with the increase of the number of cells, which provided evidence for competition between the cells. The maximal cell volume $M_{\max }$ was not dependent on the 
percentage of wild species genome. On the contrary, the maximal size of the population $n_{\max }$ was smaller for $P$. davidiana, than for the other three groups, indicating fewer competitive units in the wild species. The parameter $\alpha$ displayed smaller values for $P$. davidiana, indicating higher competition between cells than for the commercial cultivar group. Most of the data are located in the region of undercompensating densitydependence, $\mathrm{n}_{\text {opt }}$ being higher than most of the cell number observed (Fig. 4).

3. QTLs of competition. A previously described tomato population (Prudent et al., 2009), comprising 20 introgression lines derived from the introgression of Solanum chmielewskii into $S$. lycopersicum cv. Moneyberg has been used. Parameter $\beta$ has been estimated for each line using the Prudent et al. (2013) model, and a QTL detection was done following this estimation. Most of the QTLs for fresh weight were colocalized with QTLs for $\beta$ which indicates that susceptibility to competition for resources may be an important process underlying fruit fresh weight in tomato (Fig.5).

\section{CONCLUSIONS}

We have proposed a simple theory of fruit mass production that considers organs pertaining to a population, which compete for resources. The theory is applicable to a large range of plants and of scales from the cell to the plant population. Our analysis shows that general trends exist whatever the scale and the plant species. Firstly, the mass of the units of the population decreases almost always with the number of units. It means that there is competition for the resource between the units of the population. A second important tendency is that the mass of the population usually increases with the number of its elements. It means that there is under-compensating competition: the resource is always rather large to allow the increase of the population mass in spite of the competition. The theory is useful to analyse the effect of resources and genetic control on competition for fruit growth.

\section{ACKNOWLEDGEMENTS}

\section{Literature Cited}

We thank N. Bertin for her participation to this work.

Antognozzi, E., Tombesi, A., Ferranti, F. and Frenguelli, G. 1991. Influence of sink competition on peduncle histogenesis in kiwifruit. New Zeal. J. Crop Hort. 19: 433439.

Begon, M., Harper, J. L. and Townsend, C.R. 1996. Ecology. Blackwell Science, Oxford, UK.

Génard, M., Baret, F. and Simon, D. 2000. A 3D peach canopy model used to evaluate the effect of tree architecture and density on photosynthesis at a range of scales. Ecol. Model. 128: 197-209.

Lescourret, F. and Génard, M. 2003. A multi-level theory of competition for resources applied to fruit production. Ecoscience 10: 334-341

Prudent, M., Causse, M., Génard, M., Tripodi, P., Grandillo, S. and Bertin, N. 2009. Genetic and physiological analysis of tomato fruit weight and composition: influence of carbon availability on QTL detection. J. Exp. Bot. 60: 923-937.

Prudent, M., Dai, Z., Génard, M., Bertin, N., Causse, M. and Vivin, P. 2013 Resource competition modulates the seed number-fruit size relationship in a genotypedependent manner: a modeling approach in grape and tomato. Ecol. Model. (in press) DOI: 10.1016/j.ecolmodel.2013.10.023. 
Quilot, B. and Génard, M. 2008. Is competition between mesocarp cells of peach fruits affected by the percentage of wild species (Prunus davidiana) genome? J. Plant Res. 121: 55-63.

\section{Figures}

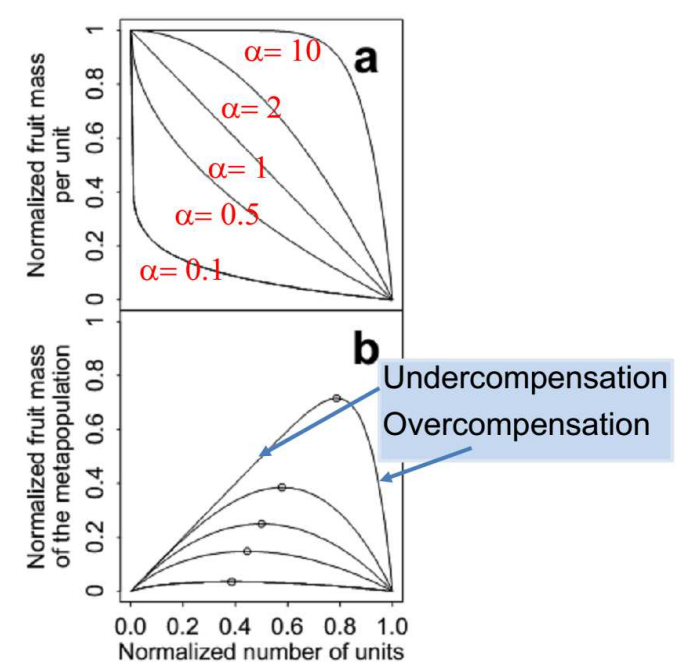

Fig. 1. Plots of fruit mass against number of units according to the theory of Lescourret and Génard (2003). Axes are normalized by the maximal number and mass of units. Circles indicate $\mathrm{n}_{\mathrm{opt}}$ values.

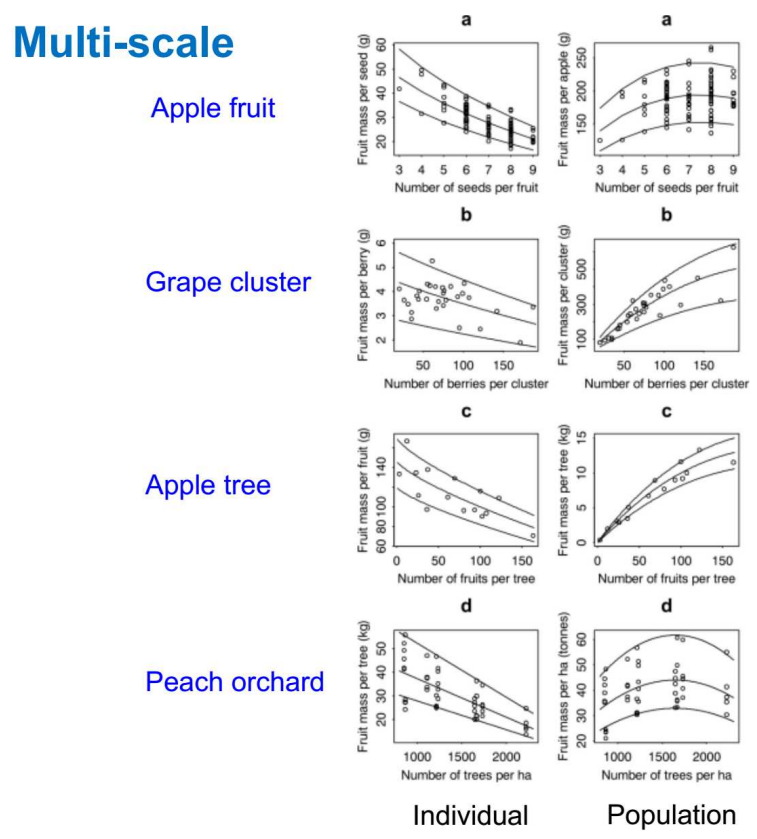

Fig. 2. Plots of number of units in the population against either fruit mass per unit (left column) or total fruit mass of the population (right column). Circles are real data and lines are Lescourret and Génard (2003) theory predictions. The three lines on each graph correspond to maximal, mean and minimal values of parameter $M_{\max }$. The graphs refer to 
'Royal Gala' apple fruits (a), 'Muscat' grape berries (b), 'Summered' apple trees (c) and 'Yanco Queen' peach populations (d).

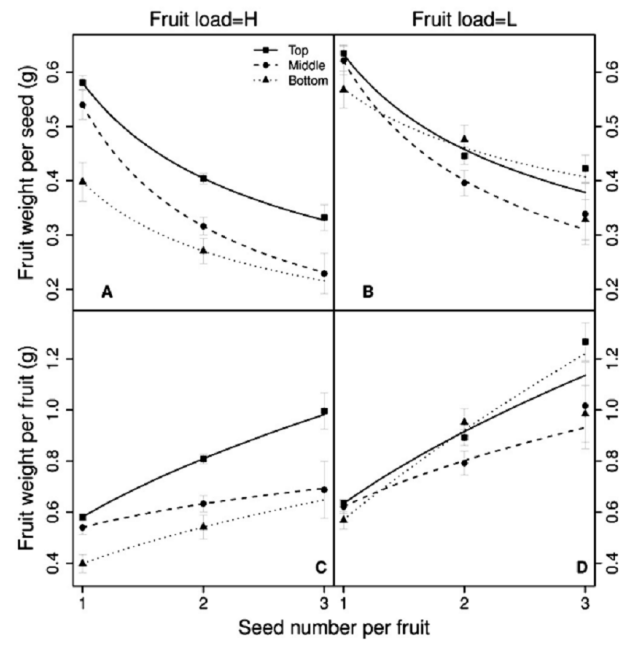

Fig. 3. Fruit load affects the relationship between seed number and berry size for several berry positions in grape. Observed values (points) are compared with the Prudent et al. (2013) model predictions (lines).

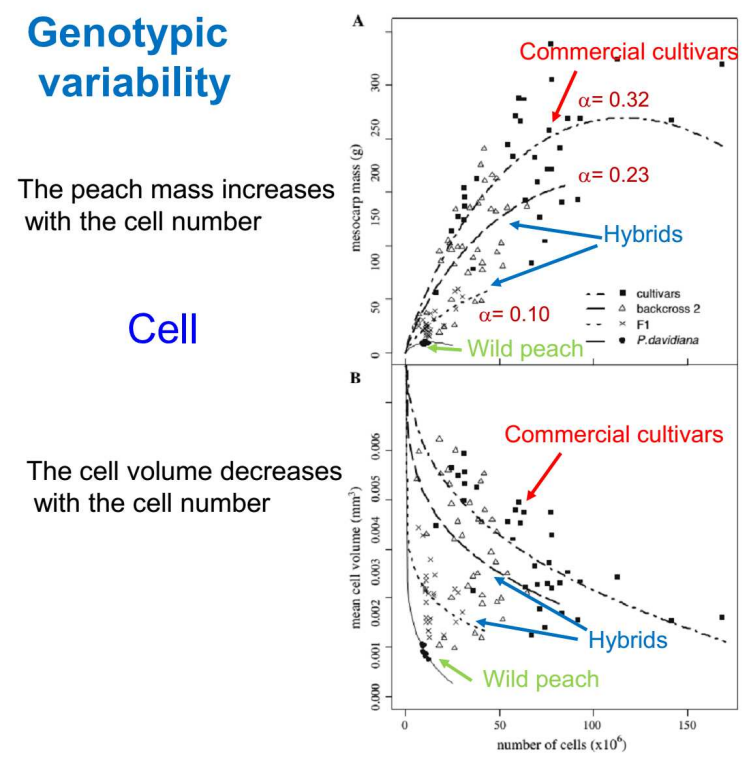

Fig. 4. Relationships between the number of cells in peach mesocarp and (A) the mesocarp mass of fruits and (B) the mean cell volume, from four groups of different levels from wild species genome. The lines represent the predictions calculated from Lescourret and Génard (2003) model. 
Chr. 8

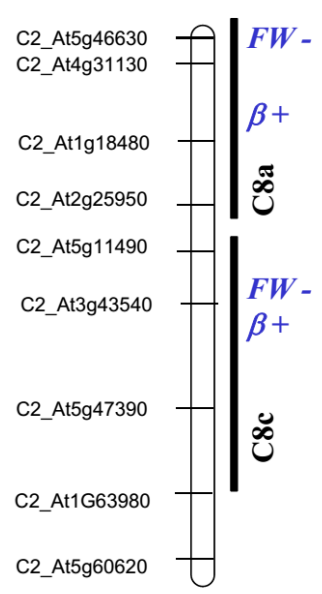

$87 \mathrm{cM}$
Chr. 9
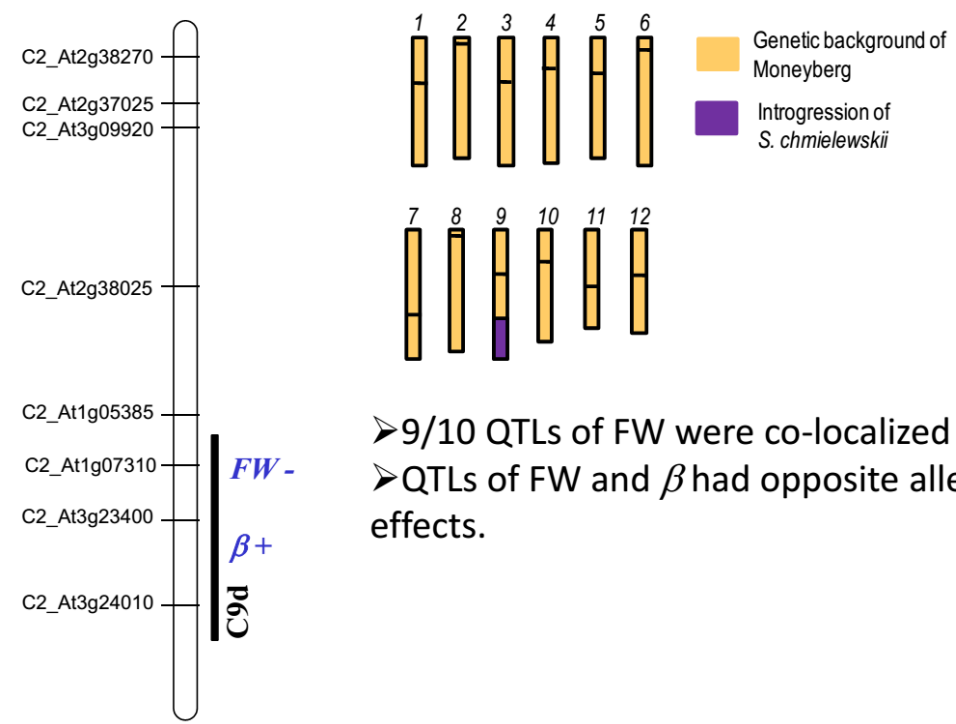

$>9 / 10$ QTLs of FW were co-localized with $\beta$. $>$ QTLs of FW and $\beta$ had opposite allele effects.

Fig. 5. Tomato genetic map for 3 lines (C8a, C8c, C9d), showing the locations of QTLs for the parameter $\beta$ detected in tomato genotypes carrying a single introgressed fragment of the wild S. chmielewskii tomato. QTL previously detected on fruit fresh weight (FW) in Prudent et al. (2009) are indicated. (-) and (+) indicate negative and positive effects, respectively, of the wild $S$. chmielewskii alleles on the trait. 